\title{
Fire research and the global village ${ }^{1}$
}

\author{
by M. G. Weber ${ }^{2}$
}

International fire research activities, priorities, constraints and opportunities are examined from a late 20 th century vantage point. Recent accomplishments in computer technology are identified as the single most important phenomenon responsible for the advancement of the science and "shrinking" of the globe. Computer technology and the global research cooperation it has engendered are put within the context of societal demands and research funding limitations impacting on fire research activities in the various research organisations. Society's insistence on fiscal responsibility in the conduct of science is symptomatic of a greater need to balance increased demand for resources by a growing world population with the sustainability imperative. Fire research and its practitioners are well positioned to contribute meaningfully to the debate on ecosystem management, restoration and sustainability currently underway in the global village.

Key words: fire research, computer applications, international fire research activities, fire research and science policy, ecosystem management, sustainability
La recherche internationale sur les feux, ses priorités, ses contraintes, et ses possibilités sont examinées avec le point de vue d'une perspective de fin du 20 ème siècle. Les récentes percés en technologie informatique sont identifiées comme la principale raison de l'avancement de cette science et la globalisation des enjeux. La technologie informatique et la coopération qu'elle a engendré sont mises dans le contexte des demandes de la société et des restrictions budgétaires ayant un impact sur les activités de differents organismes de recherche. L'insistence de la société sur la responsabilité fiscale dans la conduite de cette science est symptomatique du besoin d'équilibrer la demande croissante en resource pour la population mondiale en constante augmentation et les imperatifs du développement durable. La recherche sur les feux et ses participants sont bien positionnés pour contribuer de facon appréciable au débat sur la gestion des écosystèmes, la restauration des écosystèmes perturbés et le développement durable qui est actuellement en cours dans le village globale.

\section{Introduction}

The theme of this paper was originally assigned to me for a keynote address which was to deal with forest fire research activities underway around the world. The approach was left up to the speaker and I decided early on that the talk would encompass more than a simple enumeration of fire research activities currently undertaken planet-wide. The title chosen was to draw attention to the fact that, as in all other endeavours, scientific or otherwise, the results of our actions as well as our inertia, reverberate through the global village.

The physical fire research structures of the global village are visually identifiable as the buildings, laboratories and field sites where we spend our working days and nights. The administrative and financial support beams may be perceived as inconspicuous or obtrusive, as the case may be, but they are there. What is not so readily discernible or what cannot be described as easily, is the nature of the fabric that holds the edifice together. It is made up of many strands, each one crucial in its own right and contributing to the overall strength of the structure. The most important components, of course, are the people labouring within those walls. We, in turn, are tied together, if not by similar scientific training, then by the collective aspiration to do research on fire-related matters, whether

\footnotetext{
${ }^{1}$ Modified from a keynote address given at the 2 nd International Conference on Forest Fire Research. 21-25 November 1994. Coimbra, Portugal.

${ }^{2}$ Canadian Forest Service, St. John's, Newfoundland, Canada A1C 5X8.
}

physical, biological, economical, or social. The other elements which bind us together are the technological tools at our disposal, combined with the universal demand that our research be germane to contemporary societal constraints or priorities dictated by a diminishing resource base.

This paper will examine the significance of these two unifying agents, technological advances and societal demands, to international fire research, how they affect the way we practice the art and science of fire research and what difference, if any, we might make to the manner in which business is done in the global village.

\section{Late 20th Century Technology and International Fire Research}

The single most important phenomenon responsible for "shrinking" the planet into a global village has been the development of computer technology and its incorporation into the areas of communication, scientific computing and transportation. The impacts of late 20th century advances in computer technology and computing have been particularly profound on the conduct of science. These impacts now extend far beyond simple numerical computations and the speed with which they are done, but extend into such domains as complex simulations and knowledge and information retrieval (Brauman $e t$ al. 1994).

Computer technology allowed for great strides to be made in such complex fields as decision support, fire modelling, fire 
and chaos theory, artificial intelligence, and the use of General Circulation Models (GCM) in predicting potential impacts of global change on forest fire phenomena. The whole area of modern fire management systems research and its component subsystems dealing with fuels, weather forecasting, danger rating, fire occurrence and fire behaviour prediction, etc. was similarly greatly advanced through the massive application of computing power. The use of global positioning systems (GPS), originally a strictly military application, has been vigorously embraced by those fire researchers relying on the relocation of field sites for monitoring of short or long-term experiments from the ground or by remote sensing. Fire research has similarly benefitted from collaborating with workers from other branches of science and adapting their technologies successfully and efficiently to its own requirements. One area which immediately comes to mind is geographic information systems (GIS), now routinely used in fire management research and its applications.

Other advances in computer applications which the scientific community was quick to exploit and put to its own uses were the development of networking capabilities and specialized servers available on the Internet. A specific example, of particular interest to fire researchers globally, is FireNet which can be accessed through World Wide Web using Mosaic or other software by anyone with a desktop computer and a link to the Internet (Green et al. 1993). FireNet is an international network for landscape fire information. It concerns all aspects of fire science and management, including fire behaviour, fire weather, fire prevention, initiation and suppression, plant and animal responses to fire, and all aspects of fire effects. The first FireNet node was established at the Australian National University in 1993 by Malcolm Gill, David Green, and Chris Trevitt.

It is no longer necessary to be a computer expert to ride the information highway and roam the networks in search of information at any level of complexity or diversity. On the contrary, the explosive increase in the volume of information that has become available within a very short period of time can be compared to the adjustments necessary when switching from a trickle of water to drinking from a fire hose. The judicious use of computer networks for the advancement of our science therefore becomes more important than the mastery of the technology in and of itself. For example, you don't have to be an electrical engineer to use the telephone, just as you don't have to be a computer expert to use electronic mail. All that is required is intelligent use of the tool and your time. No other recent technological development has contributed more to bringing us closer together than the use of E-mail and computer networks.

Besides the use of computers for networking, computing, in the classical sense, remains at the heart of our science. For example, recent past issues of the International Journal of Wildland Fire each contained at least one article dealing with the use of computing power in fire research per se (Richardson et al 1994; Baird et al. 1994) or depended strongly on the heavy application of computer resources (Beer 1993). It is probably safe to speculate that reliance on state-of-the-art computer systems is bound to increase in the conduct of fire research coupled with an increased dependence on computer technology on the part of the operational agencies involved in day-to-day fire management activities.
Singing the praises of computer systems as the ultimate research and networking tool must always be tempered by a caveat: no matter how fancy the hardware and software we use to treat our data, it does not absolve us of the responsibility that the research which generated the numbers be of the highest quality. In a discipline like fire research, the old adage "garbage in, garbage out" takes on a horrifying new dimension when lives are at stake or even lost, as so tragically happened during recent wildfires in the United States, Australia, Argentina and Spain. 1994 was a very bad year for fire fighters. Like other specialists in those branches of science and engineering, which put people and their welfare at the centre of their thinking, we have to be forever cognizant that the science and the mathematics behind the computations are critical.

There is another important component of fire research which sets it apart from other disciplines in many ways, which has benefitted significantly from late 20th century technological advances, and which has greatly contributed to our transformation into global villagers. This is the second of the "two solitudes in forest fire research" referred to by C.E. Van Wagner at the 1971 IUFRO Congress in Gainesville, Florida, namely, field work. At that time Van Wagner (1971) urged that laboratory or modelling studies, the twin solitude, include explicit considerations as to their applicability to the outdoor world. Field studies, in turn, should refer to and make use of the results of theoretical and modelling work wherever possible. In this way, Van Wagner concluded, the most efficient progress would be made to advance the science. Maybe the two solitudes can never be made to mesh perfectly, but I think it is safe to say that we have made noticeable headway in linking the two in ways that have greatly increased our understanding of fire science both physical and biological.

There are several large scale field experiments presently underway which graphically illustrate the level of complexity to which fire research has been taken today. These truly international, or even intercontinental, experiments use state-of-the-art technology on the ground, in the air and in space. All necessary equipment, the instruments, sensors and data loggers, are operated by men and women of varied national affiliations, whose expertise may run the gamut from knowledge of proper soil sampling procedures to up and downloading computers and data bank management.

Ongoing international fire research efforts were most recently reviewed in detail at the 12 th Conference on Fire and Forest Meteorology on Jekyll Island, Georgia, by Johann Goldammer (1993). The experiments (Table 1) are themselves embedded in a larger hierarchy of global research activities represented by such familiar undertakings as the IGBP (International Geosphere-Biosphere Program), IGAC (International Global Atmospheric Chemistry Project), and BIBEX (Biomass Burning Experiment). These are truly globe-spanning experiments drawing on the expertise of fire researchers and scientists from allied disciplines worldwide. Field campaigns for the experiments have already been carried out or are planned for Siberia, northern Canada, southern and eastern Africa, South America and Southeast Asia. Scientific specialization of the participants in these experiments include fire ecology and behaviour, atmospheric chemistry, climatology and remote sensing in addition to computer applications such as geographic information systems (GIS). The reason for assembling such a formidable international contingent of experts is the realization that global 


\begin{tabular}{lcc}
\hline Table 1. International fire research activities \\
\hline Acronym & Title & Participating countries \\
\hline SAFARI & $\begin{array}{c}\text { South Africa Fire Atmosphere } \\
\text { Research Initiative }\end{array}$ & $\begin{array}{c}\text { Canada } \\
\text { Germany }\end{array}$ \\
& & $\begin{array}{c}\text { Republic of South Africa } \\
\text { United States of America }\end{array}$ \\
IBFRA & $\begin{array}{c}\text { International Boreal Forest } \\
\text { Research Association }\end{array}$ & $\begin{array}{c}\text { Belgium } \\
\text { Canada } \\
\text { China }\end{array}$ \\
& & Finland \\
FIRESCAN & Fire Research Campaign & Norway \\
& Asia-North & Germany \\
& & Sweden \\
& & Russia \\
SEAFIRE & & United States of America \\
& South East Asia & Southeast Asian Countries \\
FIRESCHEME & Fire Experiment & \\
& Fire Information Systems & Mediterranean Countries \\
& Research in the Ecology, & \\
& Socio-Culture and History \\
of the Mediterranean & \\
& Environment & \\
\hline
\end{tabular}

biomass burning has planet-wide repercussions and affects the life support systems of all global villagers. The duration of some of the experiments will extend to the end of this century and beyond. Findings from all of them will hopefully contribute towards the formulation of a strategy which may help us to maintain, establish or re-establish local levels of ecosystem health acceptable to everybody.

This type of global undertaking would simply have been impossible not too long ago because of technical limitations in the areas of communications and transportation. Even today, tremendous organizational obstacles and logistical bottlenecks have to be overcome during the planning and field campaign stages of these experiments. Also, the requirement for modern technology and high speed computers does not end with the execution of the experiment per se. Timely sample preparation and processing, data management and manipulation, air and satellite imagery processing, etc. are crucial stages in a system where the integrity of the data base is of overriding importance.

In our enthusiasm to praise the technology of the day, we should never overlook the fact that this technology was originally designed, then built, and later run and maintained, by people. Keeping this in mind acts as a reminder that people represent the bottom line, evaluating and presumably deriving some sort of benefit from our work, and secondly serves to reinforce the notion that people have to take responsibility for the consequences of their actions, including failures, rather than being quick to pin the blame on a piece of equipment or the current state of technology.

\section{Late 20th Century Societal Demands and International Fire Research}

Having brought the focus back to people, it seems appropriate to examine fire research in light of the second driving force mentioned earlier, namely, the societal demands placed on us and our outputs, and to what extend these demands have shaped our activities. In fire research, as in other scientific disciplines, there are some who pursue a course of inquiry dealing with problems of a fundamental nature and others whose effort advances the field in the area of applied research. I will not join the debate weighing the relative merits of one form of research against the other because such discourse often only serves those who want to detract from our work. I would, however, be foolhardy to ignore the growing public pressure on policy makers and research managers to enforce the demand that our research be "relevant", "mission oriented", "more applied" or whatever the term-of-the-day which denotes instantaneous applicability or profitability of results. Often these demands spring from real needs and I do not want to belittle those. What features as a frequent source of frustration to many of us, though, is the lack of understanding on the part of our masters that the product emerging at the operational end of the fire research business often went through painful formative stages in the workshops of fundamental science and engineering. Nevertheless, no amount of remonstration will obscure the present-day realities of research support in university, government and industrial laboratories, i.e., the growing public pressure for all public expenditures in science and technology to be spent on "relevant" research (Abelson 1994).

Compliance with these demands is assured with the oldest and most effective tool available to policy makers in all types of organization, the allocation of research funds at a reduced level. This reduced funding environment for research at the close of the 20th century appears to be widespread among all institutions of government, industry and universities everywhere, with no prospect of amelioration in the short run. The ultimate result of erosion in funding support need not be all bad, although short term impacts on individuals and organizations may be stressful and disruptive. Drastic change is always accompanied by stress. Industrial research and development efforts have already been slashed in many branches of industry. Government labs are being downsized, amalgamated or closed, and academic research, similarly, faces the prospects of downsizing and of adjusting curricula to the changing demands of society and future needs of students. There seems to be general consensus among the prognosticators of science policy trends that return to the status quo ante is one of the events that can safely be predicted to fail. Assuming they are correct what specifically might be the implications for fire research in general and at the international level in particular?

I believe fire research is well poised to meet these turn of the century challenges because we have a history of rising to the occasion in the past when we had to adapt to changing demands and priorities, concomitant with an increase in the level of sophistication of available technology. We probably have to become even more efficient at what we already do well such as networking and carrying out cooperative research with support from diverse funding sources. The international fire research activities mentioned above would bode well for any research community under pressure to consolidate lines of investigation and to achieve multiple goals with reduced funding. Consolidation also implies elimination of duplications in effort, standardizing equipment and training, and cooperation and sharing of resources across international boundaries. There is, no doubt, room for improvement in these areas, but we can also report some notable success stories. Informal sharing of human and other resources between participating countries is always implied in large scale international fire research efforts, like the SAFARI project, to give an example. More formal agreements at the policy level are also in place and have helped to 
foster cooperation internationally. For example, there is a formal agreement between Canada and the United States to share resources in the event of major wildfire events. This agreement has been put to good use during recent severe fire years in Canada and the U.S. through the good offices of the U.S. Forest Service's Boise Interagency Forest Fire Centre and Canada's counterpart in Winnipeg, Manitoba. As well, fire suppression technology developed in North America, such as air tankers, is used by different international agencies. Forest fire danger rating and associated decision support systems, developed in Canada, are used in Spain, New Zealand and the State of Alaska. Professionals come from all over the world to train and study new technology at the National Advanced Resources Training Center in Marana, Arizona.

This is by no means a comprehensive list of research agreements and activities between countries or agencies participating in cooperative research ventures and technological exchanges. It is merely intended to point out that these formal and informal links exist, providing the mechanism whereby limited financial resources can be stretched to their maximum usefulness in accordance with the demands placed on us by our masters.

Society's demands for fiscal responsibility on the part of scientists, and the relevance of research to contemporary problems faced by people everywhere are only symptomatic of a greater predicament confronting the global village and its occupants at the close of the millennium. This dilemma is resource depletion and ecosystem degradation associated with resource extraction. No matter whether one looks at renewable and nonrenewable resource availability trends sanguinely or with alarm, the consensus seems to be that there is reduced resources supply coupled with increased demand by growing populations. The drive to extract resources with increasing efficiency from ever shrinking aquatic and terrestrial inventories has resulted in well documented cases of local ecosystem degradation or even their destruction with sometimes global consequences. A more constructive alternative to enumerating examples and wringing of hands over past follies is an examination of the contributions fire research can make to provide solutions internationally. From what has been said so far, it would seem that the fire research community has the wherewithal to act as a knowledgeable and responsible contributor to the formulation of strategies for ecosystem management, restoration, and sustainability well into the 21 st century.

The international experiments (Table 1), currently underway or planned, are a case in point. As mentioned earlier, the expertise represented by participants from all over the world is brought to bear on a fire problem of planetary proportions, namely biomass burning and its effect on global change. The research carried out by project scientists is designed to provide insights into the following global processes: the production and transport of chemically and radiatively active gases and aerosols from biomass burning; the consequences of biomass burning on regional and global atmospheric chemistry and climate; the short- and long-term effects of fire on postfire gas exchange between terrestrial ecosystems and the atmosphere; the biogeochemical consequences of atmospheric deposition of products of biomass burning (Goldammer 1993). This is a tall order, requiring commitment and tenacity on the part of scientists and continued support on the part of the various funding agencies. The information generated by these investigations will go a long way towards accomplish- ing one of the tasks given us by our fellow villagers, that is, to provide the information base from which informed, and hopefully enlightened, policies can be formulated by the decision makers in our different societies.

On the local level, there are fire research activities ongoing, worldwide, which deal with a problem common to many of the world's ecosystems adapted to the presence of fire in some form of intensity and frequency. This problem has been given high priority for amelioration by many countries and relates to the use of fire for forest and other ecosystems' maintenance or their restoration. It includes, but is not restricted to, prescribed fire research and its application in forest ecosystem management, wildlife habitat management, range burning and use of fire in national parks and other protected areas. Although solutions to these problems will vary individually, depending on local adaptations of species and ecosystems, they share commonalities in the areas of prescription development and impact assessment, suppression, and post-fire monitoring of ecosystem structure and function to name a few. The fire research community has great technical depth and breadth to address impartially the implications of introduction or re-introduction of fire into natural or anthropogenic ecosystems for the purpose of ecosystem maintenance or restoration. There are many instances where natural resource management agencies of national governments may be well advised to draw on this expertise when formulating strategies dealing with ecosystem management of some of their renewable resources.

\section{The Communication Imperative}

Results from most of these fire research studies, carried out across the continents, are communicated like all other mainstream scientific activities; i.e. international gatherings such as the Coimbra Fire Conferences (Portugal 1990; 1994) and the resultant Proceedings, various refereed journals representing the subdisciplines of scientists involved, books, other technical publications and technology transfer notes of varying length and complexity.

The fact that the international fire research community can take advantage of additional information outlets to disseminate results, transfer technology to operational agencies and exchange information is a sign of the level of maturity achieved by fire research as a discipline. The International Journal of Wildland Fire serves as the peer reviewed means by which researchers may publish their work. Its sister publication, Wildfire, is not refereed and together with International Forest Fire News, provides an information exchange forum for fire professionals internationally. FireNet, a computer based information retrieval tool mentioned earlier, is the fire community's answer to the challenge from the information highway. As in other scientific disciplines, communicating amongst each other using all those media has greatly contributed to the shrinking of the globe and ensconced us firmly as global villagers within the community of nations. The only word of caution I would offer, is a call to all of us to strive for the same level of enthusiasm and eloquence when talking to lay audiences and policy makers that we attempt to achieve when talking to one another. After all, we do share resources, natural and otherwise, with the rest of the village and prudence demands not only to be informed, but also to provide information in a coherent fashion to our fellow villagers. 


\section{Conclusion}

Towards the end of the 20th century, international fire research, through its practitioners, has established itself as an important component of the larger scientific community. Fire researchers, globally, were quick to take advantage of fast breaking technological advances which allowed them to communicate and cooperate with great efficiency.

The international fire research activities currently underway have been initiated largely in response to widespread societal and scientific concerns regarding the lack of understanding of the mechanisms involved in the role of fire in global change. Given the relatively small community of scientists involved in fire research, compared to other fields, we have an admirable track record of research productivity by any standard of late 20th century scientific evaluation. The cohesiveness of this group, its dedication to the science and proclivity to hard work will serve us and the rest of the global village well.

The urgency of research priorities at any given time is defined by the perceptions of our fellow villagers and these perceptions will change with time. I will speculate that, in the broadest sense, "fixing things" will and must eventually replace or supersede, monitoring and describing local systems and their global connections.

The continuing challenge confronting fire researchers everywhere, is to accomplish the tasks assigned us within an environment of shrinking financial and other resources. Continued erosion of the funding base may result not only in redirection and retrenching of research activities, but may force us for the first time to point out to our masters that a level has been reached beyond which doing more with less or the same with less, is no longer possible. We may well have to get used to and pass on the message that only less can be delivered for less. If this is the scenario of the future, short or long term, we will need to keep our research tools well honed, be prepared to embrace technological innovations vigorously, and remain responsive to the needs of everyone in the global village.

\section{References}

Abelson, P.H. 1994. Reorientation of research objectives. Science 264:755.

Baird, I.A., P.C. Catling and J.R. Ive. 1994. Fire planning for wildlife management: a decision support system for Nadgee Nature Reserve, Australia. Intern. J. Wildl. Fire 4: 107-121.

Beer, T. 1993. The speed of a fire front and its dependence on wind speed. Intern. J. Wildl. Fire 3: 193-202.

Brauman, J.I., D.F. Voss and T. Appenzeller. 1994. Computing: networks and modelling. Science 265: 851.

Goldammer, J.G. 1993. Interdisciplinary research projects for developing a global fire science. pp. 6-22 In: Proceedings 12th Conference on Fire and Forest Meteorology. 26-28 October 1993, Jekyll Island, Georgia. Soc. Amer. For. SAF Publ. \#94-02. 796 pp.

Green, D.G., A.M. Gill, and A.C.F. Trevitt. 1993. FireNet. An international network for landscape fire information. Wildfire 2: 22-30. Richardson, D.M., B. Van Wilgen, D.C. Le Maitre, K.B. Higgins and G.G. Forsyth. 1994. A computer-based system for fire management in the mountains of the Cape Province, South Africa. Intern. J. Wildl. Fire 4: 17-32.

Van Wagner, C.E. 1971. Two solitudes in forest fire research. Can. For. Serv. Inf. Rep. PS-X-29. 7 pp. 